\title{
A Metal-Insulator-Semiconductor Solar Cell With High Open-Circuit Voltage Using a Stacking Structure
}

\author{
Tzu-Yueh Chang, Chun-Lung Chang, Hsin-Yu Lee, and Po-Tsung Lee
}

\begin{abstract}
A stacking metal-insulator-semiconductor (MIS) solar cell structure, which integrates an n-type MIS solar cell with a p-type MIS solar cell, is proposed to effectively enlarge the open-circuit voltage $\left(V_{\mathrm{oc}}\right)$. The measured $V_{\mathrm{oc}}$ is up to $0.71 \mathrm{~V}$ under simulated air mass 1.5 illumination $\left(100 \mathrm{~mW} / \mathrm{cm}^{2}\right)$. This $V_{\text {oc }}$ is larger than those of the n-type or p-type MIS solar cells with or without surface passivation. In this letter, we successfully demonstrate the feasibility of the $V_{\text {oc }}$ enhancement of MIS solar cells by using a stacking structure.
\end{abstract}

Index Terms-Metal-insulator-semiconductor (MIS) solar cells, open-circuit voltage, photovoltaic devices, stacking solar cells.

\section{INTRODUCTION}

M ETAL-INSULATOR-SEMICONDUCTOR (MIS) solar cells have drawn much interest for decades [1]-[12], and various approaches, such as $\operatorname{SiN}_{x}$ passivation [7], [10], have been reported to enhance their performances. In this letter, we propose a stacking MIS solar cell structure to effectively increase $V_{\text {oc }}$ by integrating an n-type MIS solar cell with a p-type MIS solar cell. Our experimental results show that this structure has potential to give high $V_{\mathrm{oc}}$ and low shortcircuit current density $\left(J_{\mathrm{sc}}\right)$ with the same output power for reducing the electrical loss in MIS solar cell applications. Since silicon is an earth-abundant element and the fabrication process is a low-temperature process, MIS solar cells with high $V_{\text {oc }}$ also have great prospects in photoelectrochemical (PEC) water splitting for hydrogen generation [13]-[15]. Although the $V_{\text {oc }}$ of conventional MIS solar cells is not high enough to match the requirement for dissociating water $(1.23 \mathrm{~V})$ [13]-[15], our proposed stacking MIS solar cell structure shows an effective way to enlarge $V_{\mathrm{oc}}$ and has potential to achieve a $V_{\mathrm{oc}}$ larger than $1.23 \mathrm{~V}$. Based on the stacking structure, we believe that MIS solar cells are very promising for PEC water splitting and that monolithic MIS photovoltaic-PEC devices can be realized in the future for converting solar energy for hydrogen production.

Manuscript received July 26, 2010; revised August 18, 2010; accepted August 23, 2010. Date of publication October 14, 2010; date of current version November 24, 2010. This work was supported in part by Taiwan's National Science Council under Contract NSC-98-3114-E-009-004-CC2. The review of this letter was arranged by Editor P. K.-L. Yu.

The authors are with the Department of Photonics and Institute of ElectroOptical Engineering, National Chiao Tung University, Hsinchu 300, Taiwan, and also with the Department of Photonics and Display Institute, National Chiao Tung University, Hsinchu 300, Taiwan (e-mail: lanceral@ ms53.hinet.net).

Color versions of one or more of the figures in this letter are available online at http://ieeexplore.ieee.org.

Digital Object Identifier 10.1109/LED.2010.2073437 (a)

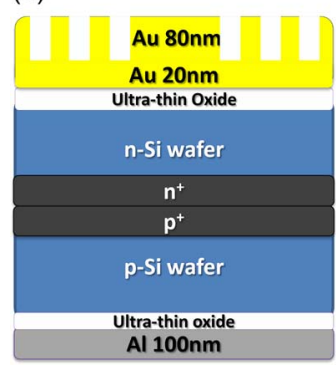

(b)

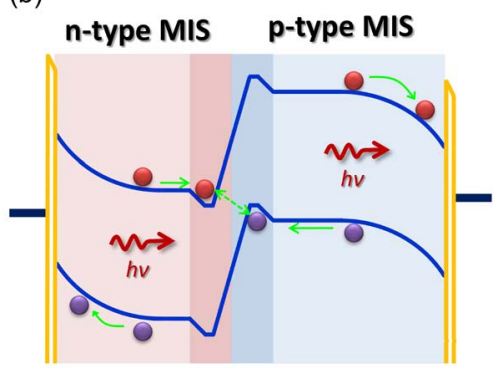

Fig. 1. (a) Illustration of the proposed stacking MIS solar cell structure. (b) Energy band diagram and operation of the stacking MIS solar cell.

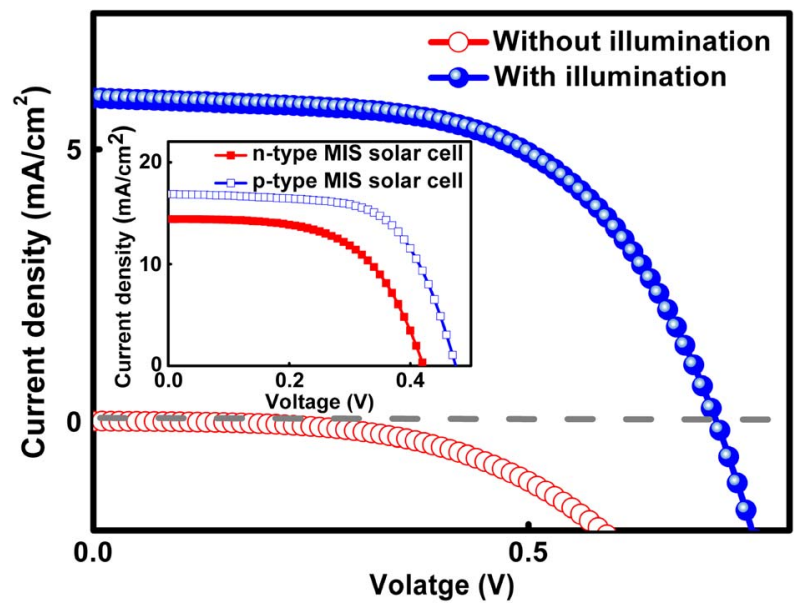

Fig. 2. $J-V$ curves of a stacking MIS solar cell with and without light illumination. Inset: $J-V$ curves of optimized n-type and p-type MIS solar cells under light illumination.

\section{EXPERIMENTS}

The proposed stacking MIS solar cell is composed of an n-type MIS solar cell as the top cell and a p-type MIS solar cell as the bottom cell with a tunneling junction in between. The structure is shown in Fig. 1(a). First, an $n-n^{+}-p^{+}-p$ sample was prepared by bonding an $n-n^{+}$Si sample and a p-p ${ }^{+}$Si sample. Both sides of the $n-n^{+}-p^{+}-p$ sample were thinned by wet etching. Since the $n-n^{+}-p^{+}-p$ sample is too fragile for thickness measurement, the thicknesses are first roughly estimated by reference Si substrates using scanning electron microscopy. The thickness of the n-type Si substrate is about $90 \mu \mathrm{m}$ and that of the p-type Si substrate is around $400 \mu \mathrm{m}$. The thickness of the n-type $\mathrm{Si}$ is designed to be much thinner than that of the p-type $\mathrm{Si}$ for current matching consideration. The optimal thickness 
TABLE I

$V_{\text {oc }}$ Comparison Between the Proposed Stacking Mis Solar Cell and Other MiS and MiS-IL Solar Cells

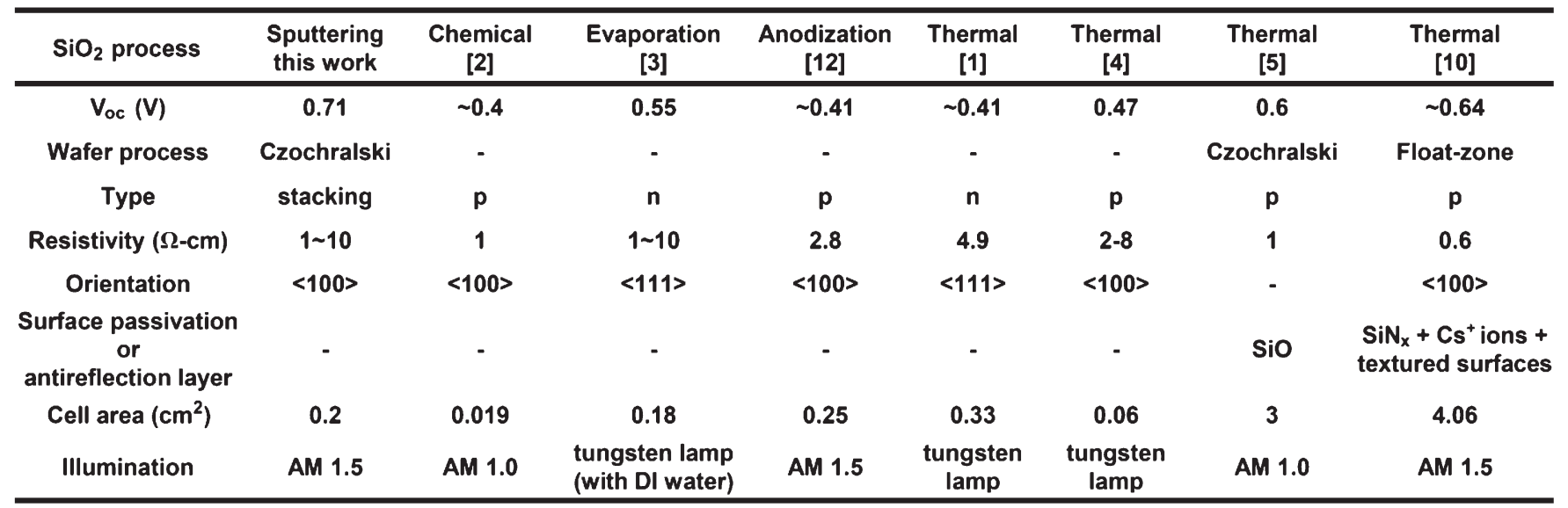

for the n-type $\mathrm{Si}$ is about $4 \mu \mathrm{m}$. Afterward, the sample was processed based on the optimized conditions obtained from the individual n-type and p-type MIS solar cells.

The thickness of the insulating layers affects the blocking efficiency of majority carriers and the tunneling probability of excess minority carriers; hence, it influences the potency of MIS solar cells. Although thermal $\mathrm{SiO}_{2}$ [1], [4]-[8], [10], chemical $\mathrm{SiO}_{2}$ [2], evaporated $\mathrm{SiO}_{x}$ [3], and $\mathrm{SiO}_{2}$ using an anodization technique [12] have been used as ultrathin insulating layers of MIS solar cells, controlling the thickness of the insulating layers well is still difficult to achieve. To easily control the thickness, radio frequency $(\mathrm{RF})$ magnetron sputtering is adopted to deposit the ultrathin $\mathrm{SiO}_{2}$ layers. The thickness of the ultrathin sputtering $\mathrm{SiO}_{2}$ layers is controlled by sputtering duration. The optimized values for the n-type and p-type silicon wafers are about 2 and $1 \mathrm{~nm}$ at $20 \mathrm{mtorr}$, respectively. A thicker sputtering $\mathrm{SiO}_{2}$ insulating layer is required for the n-type MIS solar cell to suppress the larger tunneling probability of the majority carriers.

After depositing the insulating layers, the sample was annealed in hydrogen $\left(\mathrm{H}_{2}\right)$ atmosphere at $500{ }^{\circ} \mathrm{C}$ for $1 \mathrm{~h}$ to passivate the interface traps. Then, an $\mathrm{Al}$ film as a back electrode on the p-side and a semitransparent 20-nm-thick $\mathrm{Au}$ thin film layer and a $\mathrm{Au}$ front finger electrode on the $\mathrm{n}$-side were introduced by thermal evaporation. The fabricated cell area of the stacking MIS solar cell is $0.2 \mathrm{~cm}^{2}$. The current density-voltage $(J-V)$ characteristics were measured using a Keithley 2400 source-measure unit. The photocurrent was measured under illumination from a solar simulator with an air mass 1.5 source $\left(100 \mathrm{~mW} / \mathrm{cm}^{2}\right)$. The high-frequency capacitance-voltage $(C-V)$ properties were measured by an HP 4284 precision $L C R$ meter.

\section{RESULTS AND DISCUSSION}

The operation of the proposed stacking MIS solar cell is illustrated in Fig. 1(b). The photons incident into the stacking MIS solar cell are absorbed by the top and bottom cells, and electron-hole pairs are generated. The holes in the top cell and the electrons in the bottom cell can transport to and tunnel through the ultrathin sputtering $\mathrm{SiO}_{2}$ layer of each cell and then are collected by the electrodes. In addition, the electrons in the top cell and the holes in the bottom cell can diffuse to and tunnel through the $\mathrm{n}^{+}-\mathrm{p}^{+}$junction to recombine. The resulted $V_{\mathrm{oc}}$ of the stacking MIS solar cell is given by the sum of the top and bottom cells. For this reason, the proposed stacking MIS solar cell can give a higher $V_{\mathrm{oc}}$ than an individual n-type or p-type MIS solar cell and consequently have much more promising MIS solar cell applications.

The $J-V$ curves of the proposed stacking MIS solar cell are shown in Fig. 2. In the dark, it provides the nature of a diode. Under illumination, $V_{\mathrm{oc}}=0.71 \mathrm{~V}, J_{\mathrm{sc}}=5.94 \mathrm{~mA} / \mathrm{cm}^{2}$, filling factor $=58 \%$, and efficiency $=2.47 \%$ are obtained. The $J-V$ curves under illumination of an n-type MIS solar cell and a p-type one after optimization are shown in the inset of Fig. 2. The $V_{\text {oc }}$ 's are 0.42 and $0.47 \mathrm{~V}$ for the n-type and p-type MIS solar cells, respectively. The measured $V_{\mathrm{oc}}$ of the stacking MIS solar cell is larger than that of either an n-type or a p-type MIS solar cell. For comparison, the reported $V_{\mathrm{oc}}$ of various MIS solar cells using different processes for insulating layers [1]-[5], [10], [12] are listed in Table I. Note that the $V_{\text {oc }}$ of our stacking MIS solar cell is superior to those of the n-type or p-type MIS solar cells with or without surface passivation. Since the actual thickness of the $\mathrm{n}$-type $\mathrm{Si}$ in our stacking structure is hard to measure directly, we can estimate this thickness by the measured $J_{\mathrm{sc}}$ of the stacking structure. From the $J-V$ curve of the p-type MIS solar cell shown in the inset of Fig. 2, we can roughly estimate that the thickness of the n-type $\mathrm{Si}$ is around $10 \mu \mathrm{m}$. This value is thinner than the one obtained from the reference Si substrate probably because of the inappropriate thickness estimation method and the effect of nonuniform etching during the thinning process. If we can further reduce the n-type Si thickness to around $4 \mu \mathrm{m}$ for current matching, the $J_{\mathrm{sc}}$ can be increased to $7-8 \mathrm{~mA} / \mathrm{cm}^{2}$.

The characteristics of the insulating layers play an important role in the $V_{\text {oc }}$ of the stacking MIS solar cell. For the n-type and p-type MIS solar cells with fixed ultrathin sputtering $\mathrm{SiO}_{2}$ layer thicknesses (n-type with about $2 \mathrm{~nm}$ and p-type with about $1 \mathrm{~nm}$ ) deposited under different working pressures with $\mathrm{H}_{2}$ annealing, the relationships between the $V_{\mathrm{oc}}$ and working pressure during deposition are shown in Fig. 3(a), and Fig. 3(b) shows the $C-V$ curves. For both MIS solar cells, a lower 
(a)

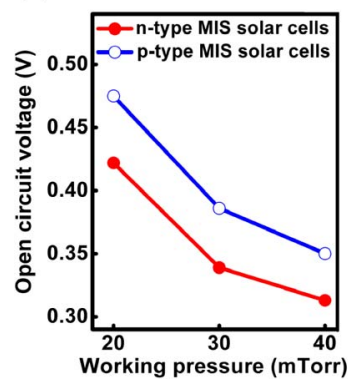

(b)

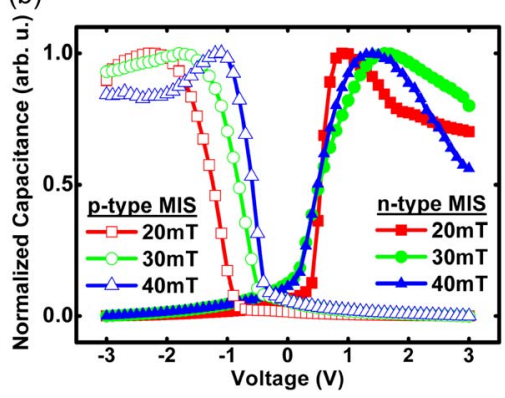

Fig. 3. (a) $V_{\text {oc }}$ and (b) $C-V$ curves of n-type and p-type MIS solar cells with fixed ultrathin sputtering $\mathrm{SiO}_{2}$ layer thicknesses (n-type with about $2 \mathrm{~nm}$ and p-type with about $1 \mathrm{~nm}$ ) deposited under different working pressures. All capacitance values are normalized by the largest value of each curve.

working pressure results in a larger $V_{\mathrm{oc}}$. At a lower working pressure, $\mathrm{Ar}^{+}$ions get more energy to sputter a $\mathrm{SiO}_{2}$ target due to a larger mean free path. As a result, larger surface charges are introduced in the ultrathin sputtering $\mathrm{SiO}_{2}$ layers on the $\mathrm{Si}$ wafers because of oxygen vacancies. Moreover, the deposition rates of the ultrathin sputtering $\mathrm{SiO}_{2}$ layers increase with decreasing working pressure in our case. A higher deposition rate reduces the ion bombardment duration at the interface. As a result, less trap states are produced, and consequently, $V_{\mathrm{Oc}}$ is enlarged. Therefore, the $C-V$ curves of the p-type MIS solar cells shift toward a more negative voltage with a lower working pressure. However, the voltage shift toward a more positive voltage is not so significant in the $C-V$ curves of the n-type MIS solar cells because of the presence of oxygen vacancies and the requirement of a thicker sputtering $\mathrm{SiO}_{2}$ insulating layer. This requirement causes a much longer ion bombardment duration than that of the p-type MIS solar cells, and then, more trap states are generated to decrease $V_{\mathrm{oc}}$.

From these results, we can conclude that the ion bombardment of RF magnetron sputtering has great influences on the interface properties and, thus, on the $V_{\text {oc }}$ of n-type or p-type MIS solar cells, which, in turn, will affect the $V_{\mathrm{oc}}$ of the stacking MIS solar cell. Therefore, it is important to optimize the fabrication process, and further enhancement of $V_{\mathrm{Oc}}$ can be expected.

\section{CONCLUSION}

In this letter, a MIS solar cell with high $V_{\text {oc }}$ using a stacking structure without surface passivation is demonstrated. The obtained $V_{\text {oc }}$ is up to $0.71 \mathrm{~V}$, greater than those of the other reported MIS solar cells. In this letter, we successfully show that the proposed stacking structure is feasible to achieve large $V_{\mathrm{oc}}$. It is expected that the performance of the proposed stacking MIS solar cell can be improved by process optimization (such as interface quality after bonding), current matching (such as decreasing the thickness of n-type $\mathrm{Si}$ ), and surface passivation (such as $\mathrm{AlO}_{x}$ for n-type $\mathrm{Si}$ and $\mathrm{SiN}_{x}$ for p-type $\mathrm{Si}$ ). Therefore, the proposed stacking MIS solar cell has great potential in the future development of solar cells and PEC water splitting.

\section{ACKNOWLEDGMENT}

The authors would like to thank Prof. M. C. Lin from the Department of Applied Chemistry and Center for Interdisciplinary Molecular Science, National Chiao Tung University, Taiwan, and Prof. L. C. Lee from the Department of Electrical and Computer Engineering, San Diego State University, USA, for the fruitful discussions.

\section{REFERENCES}

[1] D. R. Lillington and W. G. Townsend, "Effects of interfacial oxide layers on the performance of silicon Schottky-barrier solar cells," Appl. Phys. Lett., vol. 28, no. 2, pp. 97-98, Jan. 1976.

[2] A. H. M. Kipperman and M. H. Omar, "Improved efficiency of MISsilicon solar cells by HF treatment of the oxide layer," Appl. Phys. Lett., vol. 28, no. 10, pp. 620-621, May 1976.

[3] J. P. Ponpon and P. Siffert, "Open-circuit voltage of MIS silicon solar cells," J. Appl. Phys., vol. 47, no. 7, pp. 3248-3251, Jul. 1976.

[4] D. L. Pulfrey, "A minority carrier MIS solar cell," Solid State Electron., vol. 20, no. 5, pp. 455-457, May 1977.

[5] R. B. Godfrey and M. A. Green, "655 mV open-circuit voltage, 17.6\% efficient silicon MIS solar cells," Appl. Phys. Lett., vol. 34, no. 11, pp. 790-793, Jun. 1979.

[6] R. E. Thomas, R. B. North, and C. E. Norman, "Low-cost high-efficiency MIS/inversion layer solar cells," IEEE Electron Device Lett., vol. EDL-1, no. 5, pp. 79-80, May 1980 .

[7] R. Hezel and R. Schörner, "Plasma Si nitride-A promising dielectric to achieve high-quality silicon MIS/IL solar cells," J. Appl. Phys., vol. 52, no. 4, pp. 3076-3079, Apr. 1981.

[8] W. A. Anderson, G. Rajeswaran, V. J. Rao, and M. Thayer, "Cr-MIS solar cells using thin epitaxial silicon grown on poly-silicon substrates," IEEE Electron Device Lett., vol. EDL-2, no. 10, pp. 271-274, Oct. 1981.

[9] A. W. Blakers, M. A. Green, and T. Szpitalak, "Surface damage caused by electron-beam metallization of high open-circuit voltage solar cells," IEEE Electron Device Lett., vol. EDL-5, no. 7, pp. 246-247, Jul. 1984.

[10] M. Grauvogl, A. G. Aberle, and R. Hezel, "17.1\% efficient metalinsulator-semiconductor inversion layer silicon solar cells using truncated pyramids," Appl. Phys. Lett., vol. 69, no. 10, pp. 1462-1464, Sep. 1996.

[11] B. Kuhlmann, A. G. Aberle, R. Hezel, and G. Heiser, "Simulation and optimization of metal-insulator-semiconductor inversion-layer silicon solar cells," IEEE Trans. Electron Devices, vol. 47, no. 11, pp. 2167-2178, Nov. 2000.

[12] C.-Y. Wang and J.-G. Hwu, "Metal-oxide-semiconductor structure solar cell prepared by low-temperature $\left(<400{ }^{\circ} \mathrm{C}\right)$ anodization technique," J. Electrochem. Soc., vol. 156, no. 3, pp. H181-H183, Jan. 2009.

[13] A. J. Nozik, "p-n photoelectrolysis cells," Appl. Phys. Lett., vol. 29, no. 3, pp. 150-153, Aug. 1976.

[14] O. Khaselev and J. A. Turner, "A monolithic, photovoltaicphotoelectrochemical device for hydrogen production via water splitting," Science, vol. 280, no. 5362, pp. 425-427, Apr. 1998.

[15] U. S. Avachat, A. H. Jahagirdar, and N. G. Dhere, "Multiple bandgap combination of thin film photovoltaic cells and a photoanode for efficient hydrogen and oxygen generation by water splitting," Sol. Energy Mater. Sol. Cell, vol. 90, no. 15, pp. 2464-2470, Sep. 2006. 